\title{
Relationships between Extreme Rain Rates and Convective Intensities from the Perspectives of TRMM and WSR-88D Radars
}

\author{
AlexAndria Gingrey, AdAm VARble, AND EDWARD ZiPSER \\ Department of Atmospheric Sciences, University of Utah, Salt Lake City, Utah
}

(Manuscript received 18 August 2017, in final form 6 February 2018)

\begin{abstract}
TRMM PR 2A25, version 7 (V7), retrievals of reflectivity $Z$ and rainfall rate $R$ are compared with WSR-88D dual-polarimetric S-band radar data for 28 radars over the southeastern United States after matching their horizontal resolution and sampling. TRMM Ku-band measurements are converted to S-band approximations to more directly compare reflectivity estimates. Rain rates are approximated from WSR-88D data using the CSU-hydrometeor identification rainfall optimization (HIDRO) algorithm. Tropics-wide TRMM retrievals confirm previous findings of a low overlap fraction between extreme convective intensity, as approximated by the maximum $40-\mathrm{dBZ}$ height, and extreme near-surface rain rates. WSR-88D data also confirm this low overlap but show that it is likely higher than TRMM PR retrievals indicate. For maximum 40-dBZ echo heights that extend above the freezing level, mean WSR-88D reflectivities at low levels are approximately $2 \mathrm{~dB}$ higher than TRMM PR reflectivities. Higher WSR-88D-retrieved rain rates for a given low-level reflectivity combine with these higher low-level reflectivities for a given maximum 40 -dB $Z$ height to produce rain rates that are approximately double those retrieved by the TRMM PR for maximum $40-\mathrm{dB} Z$ heights that extend above the freezing level. TRMM PR path-integrated attenuation, and WSR-88D specific differential phase, differential reflectivity, and hail fraction indicate that the TRMM PR 2A25 V7 algorithm is possibly misidentifying low-midlevel hail and/or graupel as greater attenuating liquid, or vice versa. This misidentification, coupled with underestimation of path-integrated attenuation caused by nonuniform beamfilling and higher rain rates produced by specific differential phase (KDP) $-R$ than $Z-R$ relationships, results in low-biased $2 \mathrm{~A} 25 \mathrm{~V} 7$ rain rates in intense convection.
\end{abstract}

\section{Introduction}

The Tropical Rainfall Measuring Mission (TRMM), a joint effort between the National Aeronautics and Space Administration (NASA) and the Japanese Aerospace Exploration Agency (JAXA), provides scientists with tropics-wide precipitation retrievals from its launch in November 1997 through September 2014. To assess TRMM's accuracy, four TRMM ground validation (GV) sites were established throughout the tropics and subtropics (Marks et al. 2000; Amitai et al. 2002; Wolff et al. 2005), providing both instantaneous and monthly precipitation products. Using these sites and rain gauge networks, intensive validation efforts have been performed for TRMM rainfall estimates. These GV efforts have shown that TRMM Precipitation Radar (PR) is within $1 \mathrm{~dB}$ of ground radar measurements in cases of minimal attenuation, and in cases of higher attenuation,

Corresponding author: Alexandria Gingrey, alexandria.gingrey@ utah.edu accurate estimates of path-integrated attenuation (PIA) can be retrieved (Bolen and Chandrasekar 2000). The TRMM PR 2A25 rainfall algorithm uses a PIA estimate to adjust the measured reflectivity profile in cases of high attenuation. Kirstetter et al. (2012) found that version 7 (V7) of the 2A25 rainfall algorithm was superior to previous versions with improved rain-rate estimates over land.

Despite overall good agreement between TRMM retrievals and ground observations, TRMM PR's 2A25 rain-rate algorithm (Iguchi et al. 2000) is imperfect and potentially biased for some situations, especially for precipitation with severe convective intensity (Iguchi et al. 2009; Kozu et al. 2009). At the surface, TRMM PR attenuation-corrected reflectivities are less than measured Weather Surveillance Radar-1988 Doppler (WSR-88D) reflectivities, and in especially heavy convective precipitation, TRMM PR calculated rain rates were $19 \%$ less than those retrieved by WSR-88D (Liao and Meneghini 2009). One source for error is attenuation correction. The TRMM PR is a Ku-band radar, operating 
at a frequency of $13.8 \mathrm{GHz}$, and is therefore susceptible to significant attenuation, especially from liquid and partially melted hydrometeors. To mitigate the influences of attenuation, the TRMM PR 2A25 algorithm enacts an attenuation correction within the $2 \mathrm{~A} 25 \mathrm{~V} 7$ algorithm (Iguchi et al. 2009), utilizing the HitschfeldBordan method (Hitschfeld and Bordan 1954) in instances of low attenuation and the surface reference technique (SRT; Iguchi and Meneghini 1994; Meneghini et al. 2000) in instances of high attenuation to calculate the PIA for a given column of measured reflectivity. When applying the attenuation correction, which assumes hydrometeor phase and size distributions, errors can arise if the $0^{\circ} \mathrm{C}$ height is misrepresented (Iguchi et al. 2009). With an incorrect assumption of the melting-level height comes the misidentification of true particle phase. This is especially a problem when the assumed melting level is higher than the true melting level, resulting in ice particles being identified as liquid, which attenuates significantly more than ice does. This leads to improper parameters used in rain-rate calculations, and because ice particles attenuate less than liquid, a higher attenuation is estimated than what actually occurs at that point in the column, leaving less PIA to distribute within the remainder of the column. As previously stated, high attenuations are resolved via the SRT method, and produce an uncertainty in the calculated rain rate (Iguchi et al. 2009) stemming from potential misidentification of the melting level, inaccurate PIA estimates, and improper reflectivity-rain rate $(Z-R)$ power-law coefficients. This issue is common when the storm tops are high (Kozu et al. 2009; Iguchi et al. 2009). It follows that convectively intense, tall systems are prone to erroneous rain rates because of large PIA and uncertain water-phase profiles (Iguchi et al. 2009). There is thus no question that the TRMM PR algorithm is imperfect, especially in extreme convection and precipitation, but the extent to which it may be biased as a function of convective intensity is still unclear.

This uncertainty impacts findings such as those established in Hamada et al. (2015), a study that investigates the correlation between systems with extreme near-surface rain rate and those with extreme maximum 40-dBZ echo height, where maximum 40-dBZ echo height is used as a proxy for convective intensity (Zipser and Lutz 1994; Zipser et al. 2006). Hamada et al. (2015) discovered that little overlap exists between the "tallest" and "rainiest" thunderstorms. Because their study focuses on only the precipitation features (PFs) with the top $0.1 \%$ (99.9th percentile) most extreme PR pixel rain rates and maximum $40-\mathrm{dB} Z$ heights, potential attenuation-correction errors, as well as errors in the power-law coefficients of the $Z-R$ rain-rate calculation, could bias the magnitude of this overlap. If rain rates are being significantly underestimated because of an attenuation-correction bias, then the reported dichotomy between the tallest and rainiest storms may be exaggerated. This potential issue serves as the primary motivation for this study, investigating the overlap between extreme convective intensities and extreme precipitation rates. These extremes are often associated with severe weather systems, such as supercells and flooding events, which can have devastating societal impact. It is thus important to explore the ability of satellite observations to measure these extremes to work toward more accurately detecting extreme events, especially considering the scarcity of ground radar networks in many regions of the world where there is a strong reliance on satellite observations.

The accuracy of TRMM PR-retrieved reflectivities and rain rates can be investigated through comparison with radar observations from WSR-88Ds, which are S-band radars operating at $2.7-3 \mathrm{GHz}$, and are thus minimally impacted by attenuation in precipitation. The WSR-88Ds have dual-polarization, which provides additional information on hydrometeor characteristics that are not retrievable by TRMM, such as particle number and shape, through specific differential phase (KDP) and differential reflectivity (ZDR). The use of KDP and ZDR allows for more informed rain-rate calculations, as opposed to sole usage of $Z_{h}$. KDP provides information on the rainwater content in conditions with hail contamination or signal attenuation that are common in intense convection, and is thus superior to reflectivity for retrieving intense rain rates (e.g., Chandrasekar et al. 2008; Istok et al. 2009). ZDR, on the other hand, expresses the difference in the horizontal $\left(Z_{h}\right)$ and vertical $\left(Z_{v}\right)$ pulse power returns to the radar, where a positive $Z D R$ value indicates the presence of hydrometeors that are wider than they are tall, and a negative ZDR indicates the opposite. ZDR aids rainrate retrievals in conditions with significant numbers of oblate raindrops that produce greater $Z_{h}$ returns than $Z_{v}$ returns, producing an overestimate of rain rate if $Z_{h}$ is used alone, as in traditional $Z_{h}-R$ relationships such as those used for the TRMM PR 2A25 algorithm (e.g., Chandrasekar et al. 2008; Istok et al. 2009). In this study, the CSU-hydrometeor identification rainfall optimization (HIDRO) algorithm (Cifelli et al. 2011) is used to estimate rain rate from WSR-88D observations. The CSU-HIDRO algorithm has minimal bias in heavy rain and hail (Cifelli et al. 2011), and uses a logic chart depicted here in Fig. 1 (adapted from Fig. 3 of Cifelli et al. 2011) that incorporates $Z_{h}$, ZDR, KDP, and particle identification (PID) to decide which rainrate relationship $\left(Z_{h}-R, Z_{h}-\mathrm{ZDR}-R, R-\mathrm{ZDR}-\mathrm{KDP}\right.$, 


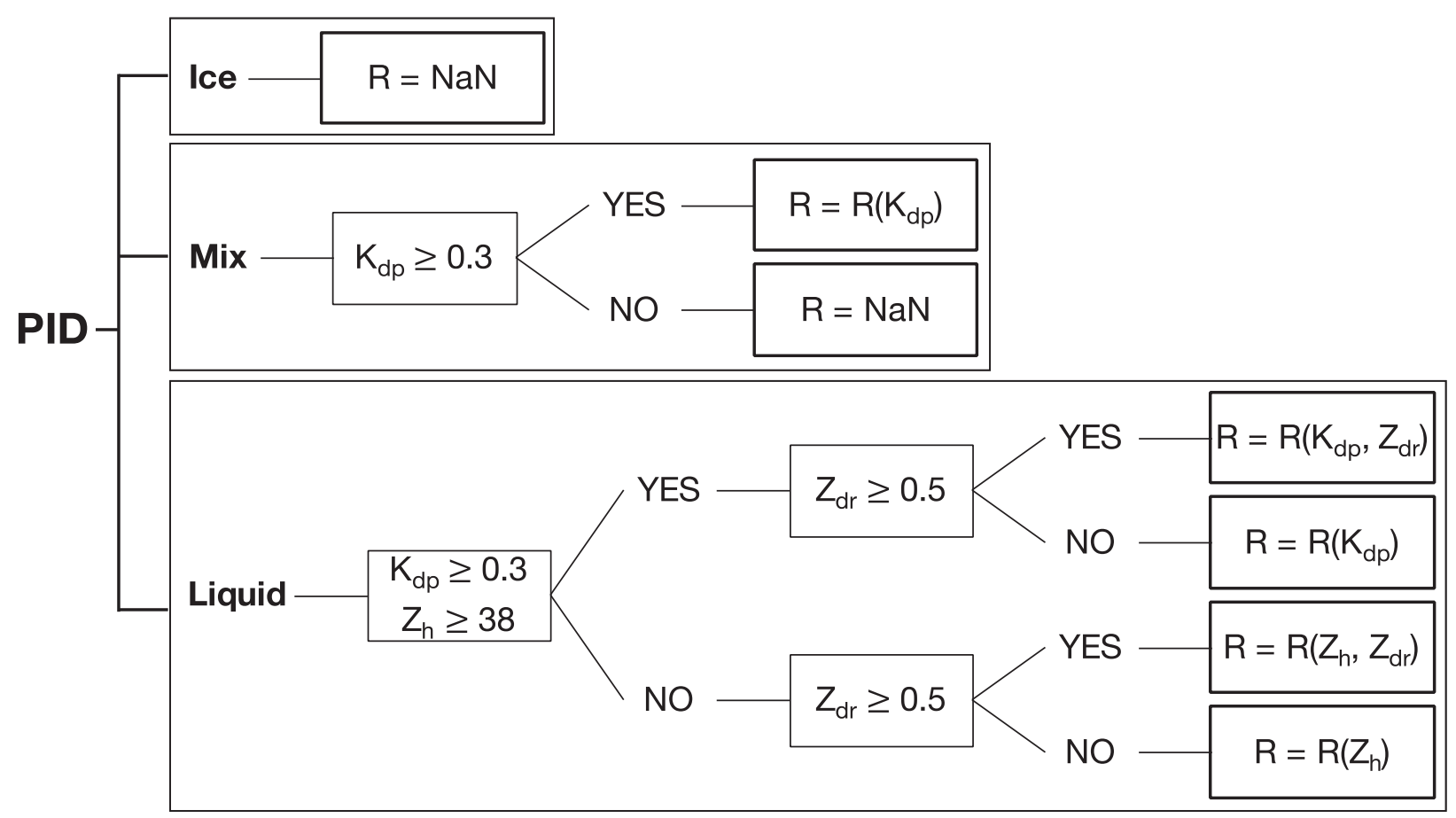

FIG. 1. Flowchart depicting the CSU-HIDRO algorithm logic. Adapted from Fig. 3 in Cifelli et al. (2011).

or $R-\mathrm{KDP}$ ) to use in different situations. PID is determined via a fuzzy-logic method that utilizes a temperature profile with a series of thresholds and ranges for a number of radar-retrieved variables, including, but not limited to, $Z_{h}, \mathrm{ZDR}, \mathrm{KDP}$, and correlation coefficient (RHO) to estimate the most likely particle type (Kessinger et al. 2003).

This work investigates relationships between maximum 40-dBZ echo heights, near-surface rain rates, and near-surface reflectivities to evaluate the robustness of the overlap magnitude between extreme convective intensity and extreme rain rates found in Hamada et al. (2015). This is done by analyzing overlap relationships in both TRMM PR and WSR-88D retrievals over the southeastern United States. Differences in TRMM and WSR-88D perspectives that indicate potential TRMM PR retrieval biases are investigated using WSR-88D KDP, ZDR, and PID observations, as well as TRMM PR 2A25 PIA estimates in an attempt to partially explain potential biases. Data and methods used are described in section 2, with results of TRMM PR observations between $36^{\circ} \mathrm{N}$ and $36^{\circ} \mathrm{S}$ in section 3 . A focused comparison of TRMM PR observations with WSR-88D observations in the southeastern United States (SEUS), as well as an investigation of WSR-88D KDP, ZDR, and hail fraction, and TRMM PR 2A25 PIA estimates, is found in section 4. Conclusions are provided in section 5 .

\section{Data and methods}

\section{a. Data}

TRMM PR retrievals observed between $36^{\circ} \mathrm{N}$ and $36^{\circ} \mathrm{S}$ are saved in the form of columns with 80 vertical levels spaced at $250 \mathrm{~m}$ between mean sea level and $19.75 \mathrm{~km}$. TRMM PR column observations are only truly vertical at nadir, and therefore columns are interpolated to a vertical coordinate from the slant path coordinate to ensure consistency in height across the dataset at all 80 height levels. The horizontal resolution of these columns is $\sim 4.5-\mathrm{km}$ postorbit boost, which occurred in August 2001. These data are archived in a number of collections, and for this study, were accessed from the University of Utah PF database (Liu et al. 2008).

The National Oceanic and Atmospheric Administration (NOAA) WSR-88D network over the SEUS does not suffer from coverage gaps to the extent that the southwestern United States does, and exhibits more frequent and more convectively intense systems than the southwestern United States (NWS Radar Operations Center 1991). Therefore, 28 radars (Table 1) from the SEUS are chosen for comparison with TRMM PR observations. WSR-88D hourly scans were accessed via the online archived inventory provided by the National Climatic and Data Center (NCDC) for June through August 2013. WSR-88Ds operate multiple scanning 
TABLE 1. Locations (city, state) of the 28 WSR-88Ds used in this study. AFB = Air Force Base.

\begin{tabular}{llll}
\hline \hline Radar & \multicolumn{1}{c}{ Location } & Radar & \multicolumn{1}{c}{ Location } \\
\hline KBMX & Birmingham, AL & KJAX & Jacksonville, FL \\
KCAE & Columbia, SC & KJGX & Robins AFB, GA \\
KCLX & Charleston, SC & KLCH & Lake Charles, LA \\
KDGX & Jackson, MS & KLIX & New Orleans, LA \\
KDYX & Dyess AFB, TX & KLZK & Little Rock, AR \\
KEOX & Fort Rucker, AL & KMOB & Mobile, AL \\
KEVX & Eglin AFB, FL & KMXX & Montgomery-Maxwell AFB, AL \\
KFDR & Frederick, OK & KNQA & Memphis, TN \\
KFFC & Atlanta, GA & KPOE & Fort Polk, LA \\
KFWS & Dallas-Fort Worth, TX & KSHV & Shreveport, LA \\
KGRK & Fort Hood, TX & KSRX & Fort Smith, AR \\
KGSP & Greenville-Spartanburg, SC & KTLH & Tallahassee, FL \\
KGWX & Columbus AFB, MS & KTLX & Oklahoma City, OK \\
KHTX & Huntsville-Hytop, AL & KVAX & Moody AFB, GA \\
\hline
\end{tabular}

strategies dependent on the current conditions at the radar. Because potential TRMM PR errors in deep convective systems are of primary concern, only WSR-88D data from convective volume coverage patterns (VCPs) 11, 211, 12, and 212 are utilized, which contain more upper-tilt elevation angles than other VCPs, which are used in nonconvective situations. While these data include stratiform columns, the focus of this study is on extreme rain rates and deep convective intensities with intense deep convection characterized by maximum $40-\mathrm{dB} Z$ echo heights higher than the $0^{\circ} \mathrm{C}$ level. These columns are unlikely to be stratiform. In addition, no explicit convective-stratiform separation is applied since a potential TRMM PR bias would bias the separation and make comparisons with WSR-88D data more difficult to interpret.

\section{b. Methodology for comparison}

TRMM PR 2A25V7 data columns and WSR-88D data columns are obtained using different observing strategies. WSR-88Ds are constantly operating over their domain, aside from when they are shut down for maintenance or experience temporary failure. TRMM $\mathrm{PR}$, however, captures a nearly instantaneous snapshot of individual systems as it orbits overhead. Therefore, for an objective comparison, individual columns of TRMM PR and WSR-88D reflectivity with computed near-surface rain rate are utilized. Rather than attempting to match TRMM and WSR-88D observations in space and time, $\sim 700000$ data columns with at least $20 \mathrm{~dB} Z$ at $1.5-\mathrm{km}$ altitude observed by TRMM PR during the months of June, July, and August (JJA) from 2002 through 2014 are assumed to be representative of the population of SEUS JJA precipitation events and are compared with an equally robust number of data columns observed by WSR-88D during JJA 2013 over the SEUS accounting for geographical sampling differences. Of these columns, over 100000 in TRMM and WSR-88D datasets contain 40-dB $Z$ echoes. WSR88Ds are well calibrated with an uncertainty of $\pm 1 \mathrm{~dB}$ (Melnikov et al. 2017).

\section{1) TRMM DATA PROCESSING}

A database of TRMM PR 2A25 data columns is created by filtering V7 data for the ensuing conditions. JJA months are selected since systems during these months are predominantly convective over the SEUS with elevated melting levels, and postboost years (2002-14) are used to maintain consistent horizontal resolution. Second, columns must have a reflectivity of $20 \mathrm{~dB} Z$ or greater at $1.5-\mathrm{km}$ altitude, indicating likely precipitation at the surface. $1.5-\mathrm{km}$ altitude above mean sea level is used to represent "near surface" in this study to maximize TRMM data retention (some columns do not have data below this level), avoid ground clutter issues, and maintain full vertical profiles for the WSR-88D out to $80 \mathrm{~km}$ away from the radars. TRMM PR columns must occur within $80 \mathrm{~km}$ of one of the WSR-88D instruments listed in Table 1 to be included in analyses, which avoids geographical biases resulting from TRMM's uniform observing at a given latitude relative to WSR-88D's nonuniform observing caused by irregularly spaced radars. For each column that meets these criteria, the following TRMM $2 \mathrm{~A} 25 \mathrm{~V} 7$ variables are saved: reflectivity at all 80 vertical levels, retrieved rain rate at $1.5-\mathrm{km}$ altitude, PIA, time, date, latitude, longitude, and the WSR-88D to which it corresponds.

The TRMM PR operates at Ku band at a frequency of $13.8 \mathrm{GHz}$, while the WSR-88D operates at $\mathrm{S}$ band at a frequency of $2.7-3 \mathrm{GHz}$. Therefore, to conduct fair 
comparisons of reflectivity retrievals between TRMM PR and WSR-88D, a second dataset of TRMM PR reflectivity converted to estimated S-band equivalent values is saved. This conversion is conducted following Cao et al. (2013) by first calculating an S-Ku reflectivity difference, and then adding this value to the initial TRMM Ku-band retrievals. Separate conversions are applied to distinctive ice and rain regions within the vertical reflectivity profile, as $\mathrm{Ku}$ band retrieves higher reflectivities than $S$ band in the rain region, and lower in the ice region when very large particles are present, because of Mie scattering effects at Ku band for particle diameters that are Rayleigh scatterers at $\mathrm{S}$ band. Because of these effects, conversion algorithms in each region are determined via simulations using assumed microphysical models for corresponding hydrometeor phase. Conversions are not calculated for the melting level, considered to be between 3.5 - and $5-\mathrm{km}$ altitude during a typical SEUS summer. These conversions have the potential to be biased should the actual hydrometeor profiles be different from what is assumed by Cao et al. (2013) in the generation of these conversions. This conversion creates a database of S-band equivalent TRMM PR reflectivities for more appropriate comparison with WSR-88D S-band reflectivities (TRMM-S).

\section{2) WSR-88D DATA PROCESSING}

WSR-88D radial data are gridded to comparable TRMM PR horizontal grid spacing using Radx software, developed by the National Center for Atmospheric Research (https://github.com/NCAR/lrose-core, https:// www.eol.ucar.edu/content/lidar-radar-open-softwareenvironment). Radial scans are first interpolated to a horizontal grid spacing of $1.125 \mathrm{~km}$ and vertical grid spacing of $250 \mathrm{~m}$, but are then horizontally averaged while conserving equivalent horizontal reflectivity to match TRMM PR's horizontal resolution of $4.5 \mathrm{~km}$.

The initial gridding produces a $160 \times 160 \times 80$ grid of reflectivity, RHO, latitude, and longitude. The same scans are additionally processed at $1.5-\mathrm{km}$ altitude to produce a corresponding $160 \times 160$ grid of rain rate, KDP, ZDR, PID, latitude, and longitude. Rain-rate calculations are completed using the aforementioned CSU-HIDRO algorithm, which is shown to have minimal bias in heavy rain and hail events in Cifelli et al. (2011). While the TRMM PR applies a $Z_{h}-R$ relationship with variable coefficients that depend on prescribed drop-size distributions (Kozu et al. 2009), the CSUHIDRO algorithm uses $Z_{h}$, PID, KDP, and ZDR to select from the following rain-rate relationships (Ryzhkov and Zrnić 1995; Brandes et al. 2001, 2002) at each grid point, as illustrated in Fig. 1:

$$
\begin{aligned}
R\left(Z_{h}\right) & =0.017\left(Z_{h}\right)^{0.7143} \\
R(\mathrm{KDP}) & =40.5(\mathrm{KDP})^{0.85} \\
R(\mathrm{KDP}, \mathrm{ZDR}) & =90.8(\mathrm{KDP})^{0.93} \times 10^{-0.169(\mathrm{ZDR}),} \\
R\left(Z_{h}, \mathrm{ZDR}\right) & =6.7 \mathrm{E}-3\left(Z_{h}\right)^{0.927} \times 10^{-0.343(\mathrm{ZDR})}
\end{aligned}
$$

As seen in Fig. 1, the CSU-HIDRO algorithm does not retrieve a rain rate when the PID indicates hail or graupel. In rain-hail or rain-graupel mixtures, rain rate is only calculated using Eq. (2.2) if KDP is greater than or equal to $0.3^{\circ} \mathrm{km}^{-1}$. It is worth noting that each of these rain-rate relationships and radar variables carry uncertainties that can impact results. The sensitivity of results to variable and coefficient values in the CSU-HIDRO algorithm, the usage of a range of other possible rain-rate relationships, and changes in data resolution is left for future work.

Before these high-resolution gridded variables are averaged down to match the $4.5-\mathrm{km}$ horizontal grid spacing of TRMM PR, the data are quality controlled based on the following criteria. First, the grid points at $1.5-\mathrm{km}$ altitude are filtered to remove nonmeteorological returns. Nonmeteorological returns are determined using both the PID and the correlation coefficient. One of 16 PIDs are chosen for each grid point via a serious of conditional thresholds and ranges for estimated temperature and a number of radar-retrieved variables, including $Z, Z$ ZD, KDP, and RHO. There are three nonmeteorological classifications for PIDS: flying insects, second trip echoes, and ground clutter. Grid points with these classifications, as well as their corresponding column in the $160 \times 160 \times 80$ grid, are set to null values. The correlation coefficient is also used to discern valid returns, as values less than 0.7 are indicative of insects, ground clutter, or rare cases of significant attenuation caused by lengthy radar beam paths through hail regions, and therefore these points as well as their corresponding columns are set to null values. This limits the possibility that reflectivity and retrieved rain rate at $1.5-\mathrm{km}$ altitude are biased because of invalid values.

To degrade the high-resolution $1.5-\mathrm{km}$ altitude $1.125-\mathrm{km}$ grids to $4.5 \mathrm{~km}$, variables in each $4 \times 4$ set of $1.125-\mathrm{km}$-spaced grid points are averaged to produce a value for the new grid point on the $4.5-\mathrm{km}$ grid. $1.125-\mathrm{km}$ grid points that do not contain valid echoes are set as null values. Reflectivity is converted from logarithmic $\mathrm{dB} Z$ units to equivalent reflectivity factor $Z_{e}$ with linear units of $\mathrm{mm}^{6} \mathrm{~m}^{-3}$ before averaging, and is converted back to $\mathrm{dB} Z$ units after averaging is completed. Averaging using $Z_{e}$ accounts for nonuniform beamfilling in a 


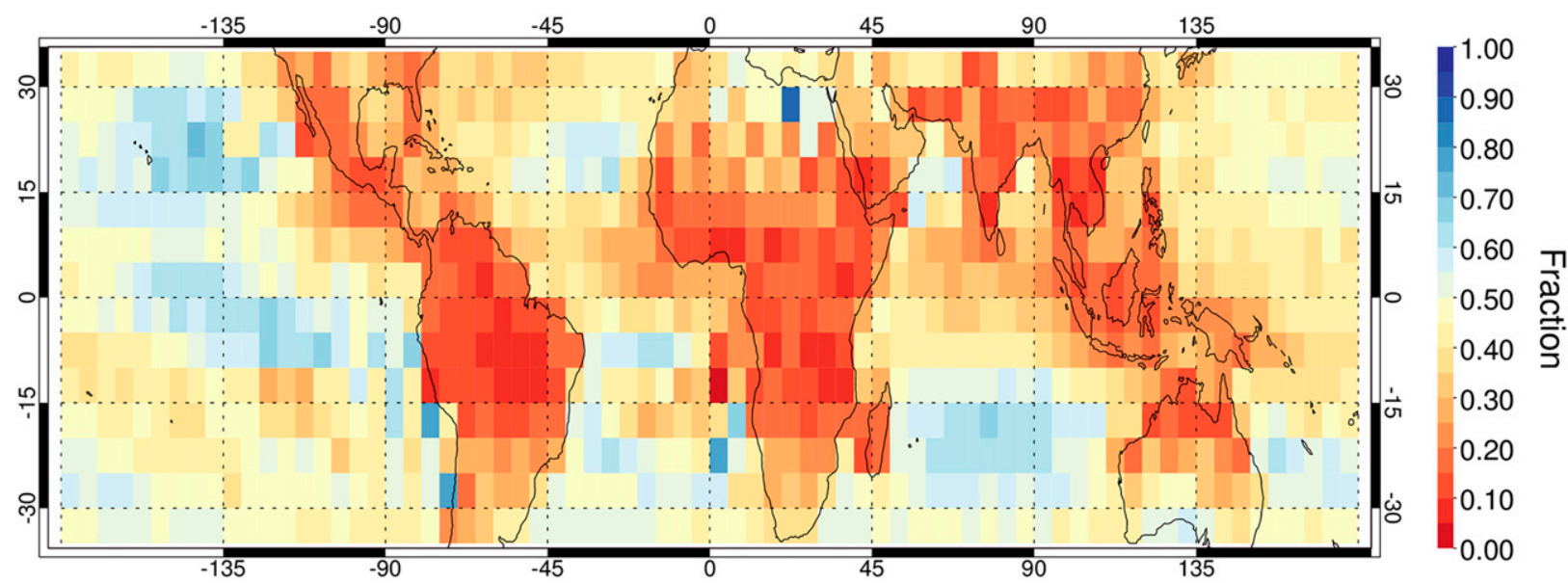

FIG. 2. Fraction of the number of TRMM-observed precipitation features in each $5^{\circ} \times 5^{\circ}$ box from 2002 to 2014 that contain both a 99 thpercentile 40-dBZ echo height and a 99th-percentile near-surface rainfall rate.

method that is consistent with the coarser resolution $(4.5 \mathrm{~km})$ of TRMM PR. For example, a $4.5-\mathrm{km}$ grid box containing finer-scale $(1.125-\mathrm{km})$ echoes with nonechoes will yield an echo of similar magnitude to that retrieved at the coarser resolution of TRMM PR. During degradation, hail fractions in each $4.5-\mathrm{km}$ grid box are defined as the fraction of the sixteen $1.125-\mathrm{km}$ spaced grid points within the $4.5-\mathrm{km}$ grid box that include graupel or hail identified by the PID. The hail fraction provides information on the extent that other retrieved variables may be affected by ice contamination at $1.5-\mathrm{km}$ altitude.

Every WSR-88D exhibits a "cone of silence" centered on the radar where the radar does not observe the entire troposphere with the altitudes not observed being dependent on range from the radar. To assure that WSR-88D columns contain data between 1.5 - and $15-\mathrm{km}$ altitudes, columns are only saved for comparison if they exist within an annulus ranging from 40 to $80 \mathrm{~km}$ from the radar location. As with TRMM, columns are retained only if they exhibit a reflectivity of $20 \mathrm{dBZ}$ or greater at $1.5-\mathrm{km}$ altitude.

Once all columns have been saved for both the TRMM PR and WSR-88D datasets, there exists a differing number of total columns in each dataset for each WSR-88D. To avoid potential biases due to the differing sample sizes of the datasets, the saved columns in the larger of the two datasets are randomly sampled down to the size of the smaller dataset for each radar. Once this subsampling at each of the 28 radars is completed, there exists a set of TRMM PR columns, TRMM-S columns, and WSR-88D columns that are ready for comparison, which are referred to as the TRMM-Ku, TRMM-S, and WSR-88D datasets, respectively.

\section{Relationships between extreme rain rates and convective intensities across the tropics and subtropics}

\section{a. TRMM PR-observed precipitation features}

Using the maximum height of the $40-\mathrm{dB} Z$ echo as a proxy for convective intensity (e.g., Zipser et al. 2006), the overlap fraction between the most convectively intense TRMM PR PFs and those with the highest nearsurface pixel rain rates is shown as a function of location in Fig. 2. The use of the 99th percentile narrows systems to those that are especially extreme, without overly restricting the number of systems being examined, and an overlap fraction of 1 indicates that in a given location, the PFs that fall within the 99th percentile of convective intensity are the same PFs that fall in the 99th percentile of near-surface pixel rain rates. This overlap perspective follows a methodology similar to that used in Hamada et al. (2015), and supports their finding that the PFs with the tallest $40-\mathrm{dBZ}$ echo heights are rarely the features with the highest near-surface rain rates, with overlap fractions mainly ranging from 0.05 to 0.4 over land. The overlap fractions over the ocean are higher, generally ranging from 0.3 to 0.6 over regions with significant rainfall. The highest overlap fractions, up to approximately 0.75 , exist in relatively dry subtropical regions of atmospheric subsidence, which are regions of stratocumulus and trade cumulus, with deep convection not only being relatively rare, but also possessing a narrower range of convective intensity than most other regions, especially land regions. This overlap contrast between land and ocean may be related to the existence of more intense convection over land than over ocean (Zipser et al. 2006). However, part of this contrast may also result from significant TRMM PR attenuation and 


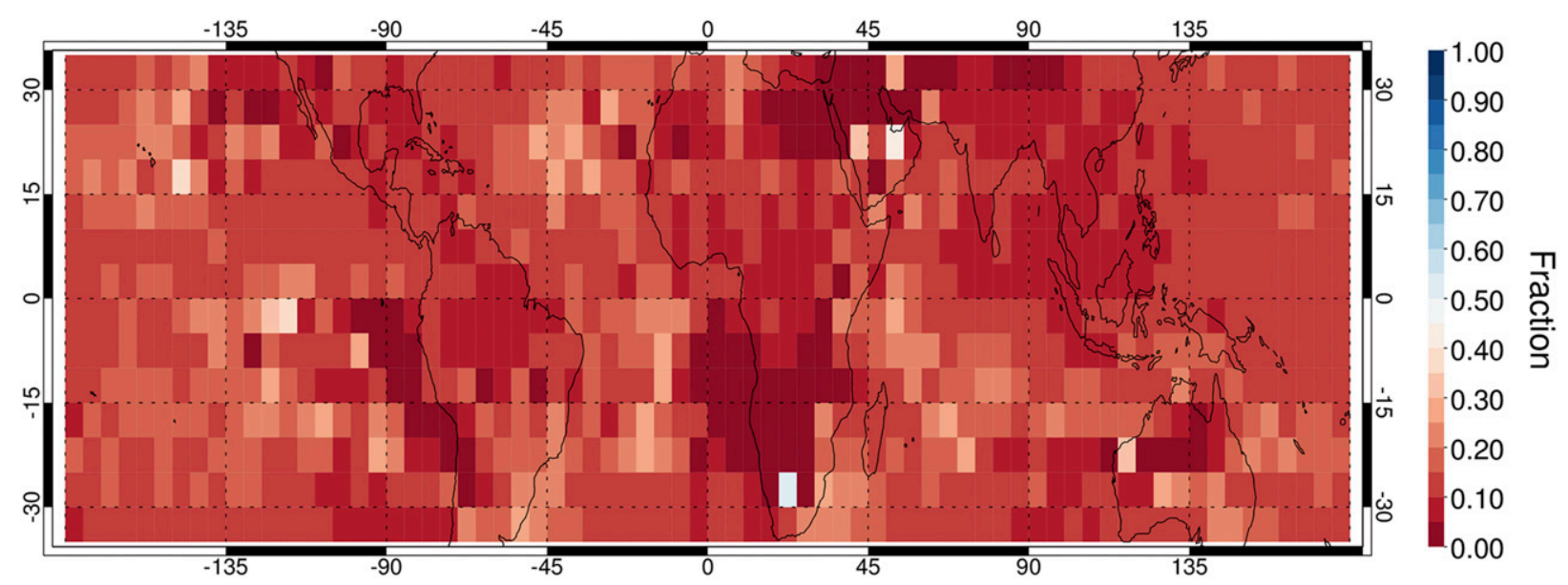

FIG. 3. As in Fig. 2, but for columns calculated using the same method as in Fig. 2.

imperfect assumptions regarding attenuation correction and $Z_{h}-R$ relationships used in intense continental deep convection, which was not addressed in Hamada et al. (2015).

Despite lower overlap fractions, there are many regions over land that express nonnegligible numbers of systems that are both in the 99th percentile of convective intensity and rain rates for that given region. The SEUS from $25^{\circ}$ to $36^{\circ} \mathrm{N}$ and from $80^{\circ}$ to $100^{\circ} \mathrm{W}$ exhibits fractions from 0.1 to 0.4 , making it a region that appears representative of overlap fractions in other land regions across the tropics and subtropics. This, coupled with the extensive geographical coverage of the WSR-88D dual-polarimetric S-band radar network, provides an opportunity for validating TRMM PR observations of convectively intense and extreme rain-rate systems with possible implications for interpretation of TRMM PR rainfall estimates across the entire tropics and subtropics.

\section{b. Individual TRMM PR-observed columns}

The same calculation of overlap fraction is shown in Fig. 3; however, rather than examining the overlap fraction of PF characteristics, we examine the overlap fractions of characteristics within individual TRMM PR-observed data columns in each $5^{\circ} \times 5^{\circ}$ box. Later comparisons between TRMM PR and WSR-88D require the use of vertical columns rather than PFs because of the differing observing geometries of the two radars. Figure 3 shows the overlap fractions of the 99thpercentile maximum $40-\mathrm{dB} Z$ heights and near-surface rain rates throughout the tropics and subtropics. Overlap fractions are much lower (not exceeding 0.5 over land) than those retrieved from the PF perspective (Fig. 2), indicating that it is very uncommon for the same vertical column observed by TRMM PR $\left(\sim 20 \mathrm{~km}^{2}\right.$ in horizontal area) to exhibit extremes in both convective intensity and rainfall rate over both land and ocean. PFs in Fig. 2 are a collection of contiguous adjacent columns, and therefore, it is much more likely that a feature than an individual column will contain columns that are in the top percentiles of both variables. Figure 3 shows that at the 99th percentile, the SEUS domain exhibits overlap fractions comparable to most other land and ocean areas, and thus, even from the column perspective, it remains a good location with a robust dataset for validating TRMM PR vertical column observations.

\section{Evaluation of TRMM-retrieved relationships over the SEUS}

\section{a. Relationships between convective intensity and rain rate}

Comparisons focus on three variables-reflectivity at $1.5-\mathrm{km}$ altitude, rain rate at $1.5-\mathrm{km}$ altitude, and the maximum height of the 40-dBZ echo in each columnfor three datasets: TRMM-Ku, TRMM-S, and WSR$88 \mathrm{D}$. The average $1.5-\mathrm{km}$ altitude reflectivity for a given maximum $40-\mathrm{dB} Z$ height is shown for each dataset, where only data from columns with a maximum $40-\mathrm{dB} Z$ height of at least $1.5 \mathrm{~km}$ are shown in Fig. 4. For maximum $40-\mathrm{dB} Z$ heights below the melting level, typically at 4-5-km altitude, all three datasets have similar $1.5-\mathrm{km}$ altitude reflectivities of $40-42 \mathrm{dBZ}$, with WSR-88D observing slightly higher values than TRMM-Ku and TRMM-S. However, for maximum 40-dBZ echoes above $5-\mathrm{km}$ altitude, differences occur between the WSR-88D and TRMM PR datasets. While reflectivity at $1.5 \mathrm{~km}$ increases with maximum $40-\mathrm{dB} Z$ height at a similar rate across the three datasets, the WSR-88D $1.5-\mathrm{km}$ altitude reflectivities are approximately $2 \mathrm{~dB}$ 


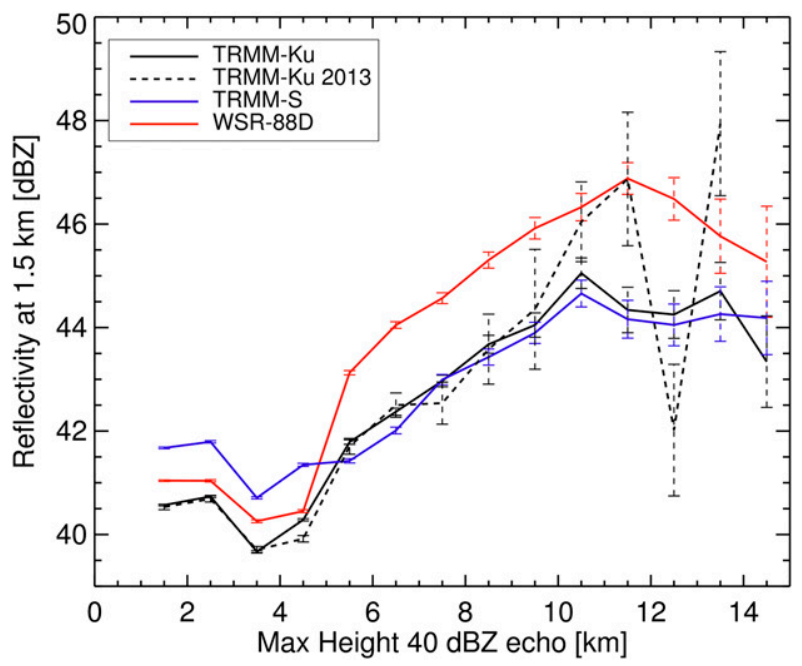

FIG. 4. Solid lines represent the average reflectivity at $1.5-\mathrm{km}$ altitude for a given bin of maximum 40-dBZ echo height. TRMM data exclusively from 2013 are shown as a black dashed line. The vertical dashed lines represent the standard error of the mean for each dataset. A minimum $40-\mathrm{dBZ}$ height threshold of $1.5 \mathrm{~km}$ is placed on the datasets and the sample sizes for each dataset are: TRMM-Ku (solid black) 130 560, TRMM-S (blue) 105 284, WSR88D (red) 124 873, and TRMM-Ku 2013 (dashed black) 12708.

higher than those of TRMM-Ku and TRMM-S for a given maximum 40-dBZ height. This offset between TRMM and WSR-88D forms quickly between 5 and $7 \mathrm{~km}$ maximum $40-\mathrm{dB} Z$ echo heights and then remains approximately constant with increasing maximum 40-dBZ height, with the conversion of TRMM-Ku to S band having no effect. Interestingly, TRMM-S $1.5-\mathrm{km}$ reflectivities are greater than TRMM-Ku $1.5-\mathrm{km}$ reflectivities when maximum $40-\mathrm{dB} Z$ heights remain below $\sim 5 \mathrm{~km}$. While the $\mathrm{Ku}$ - to S-band conversion runs the risk of misidentifying low-level hail as rain, particle misidentification would not explain the differences between TRMM PR and WSR-88D for these limited maximum $40-\mathrm{dB} Z$ heights since these systems are not likely to have hail. Additionally, Ku-band reflectivities that are at or slightly greater than $40 \mathrm{~dB} Z$ will be less than $40 \mathrm{~dB} Z$ at $S$ band, and thus will be excluded from TRMM-S samples in Fig. 4. It is therefore possible for TRMM-S reflectivities to be greater than TRMM-Ku when maximum $40-\mathrm{dB} Z$ heights are limited because TRMM-Ku and TRMM-S samples are not equivalent. This result shows that when $40-\mathrm{dB} Z$ echoes extend into ice regions, indicative of graupel or hail presence, TRMM PR low-level reflectivity is systematically lower than that measured by WSR-88D, which can impact rain rates retrieved by TRMM PR and WSR-88D.

WSR-88D data for this study come from JJA of 2013, while TRMM PR data come from JJA of 2002-13.

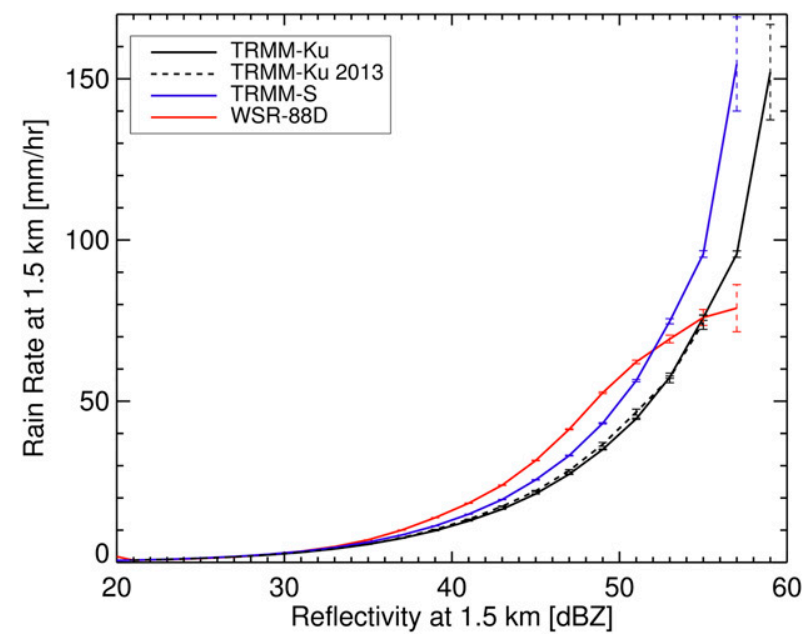

FIG. 5. As in Fig. 4, but for the average rainfall rate at $1.5-\mathrm{km}$ altitude for a given bin of reflectivity at $1.5 \mathrm{~km}$. These samples are not restricted by a threshold on the maximum $40-\mathrm{dB} Z$ height of a column. Therefore, TRMM-Ku (solid black), TRMM-S (blue), and WSR-88D (red) datasets have 700594 samples. The TRMMKu 2013 (dashed black) dataset has 77117 samples.

To show that 2013 is not an anomalous year in our dataset, TRMM-Ku data for JJA 2013 alone are shown in Figs. 4-6 as a dashed line, which is consistent with the 12-yr TRMM PR dataset (solid black) for maximum 40-dBZ echo heights below $10 \mathrm{~km}$. Thus, differences between TRMM PR and WSR-88D for maximum 40-dBZ heights below $10 \mathrm{~km}$ appear to be robust, while above 10-km altitude, small 2013 sample sizes prevent assessment of robustness, although it is likely that 2013 WSR-88D statistics of $1.5-\mathrm{km}$ reflectivity are not anomalous, since they show a similar change with maximum 40-dBZ echo height as TRMM PR 2002-13 statistics. Therefore, JJA 2013 is deemed to have sufficient and representative data to represent WSR-88D column statistics and be comparable to 2002-13 TRMM data.

The average rainfall rate for a given reflectivity at $1.5-\mathrm{km}$ altitude is shown in Fig. 5, with no requirement placed on maximum $40-\mathrm{dB} Z$ height. All three datasets have similar rain rates as a function of reflectivity below $\sim 33 \mathrm{dBZ}$. However, above $33 \mathrm{dBZ}$, the rain rates as a function of reflectivity begin to diverge with WSR-88D increasing the most quickly with reflectivity, followed by TRMM-S and finally TRMM-Ku. This results in an increasing gap between the calculated rain rate from WSR-88D and TRMM PR as 1.5-km altitude reflectivity increases. This gap is especially prevalent at $1.5-\mathrm{km}$ altitude reflectivities near $50 \mathrm{dBZ}$, with mean WSR-88D $1.5-\mathrm{km}$ rain rates of $\sim 60 \mathrm{~mm} \mathrm{~h}^{-1}$ and mean TRMM-Ku rain rates of only $\sim 40 \mathrm{~mm} \mathrm{~h}^{-1}$. These differences can be attributed to the different methods that WSR-88D and TRMM PR use to calculate rain rate. Where the TRMM 


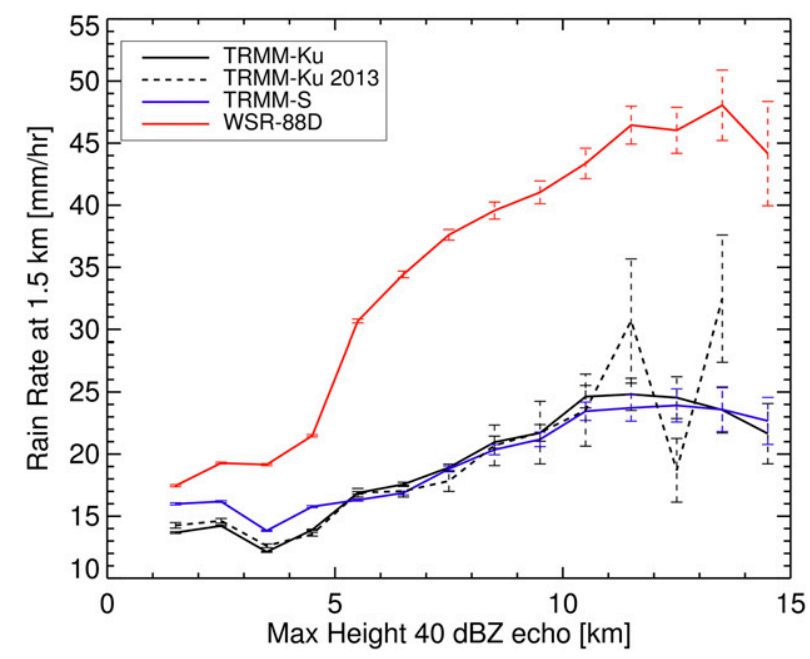

FIG. 6. As in Fig. 4, but for the average rainfall rate at $1.5-\mathrm{km}$ altitude for a given bin of maximum $40-\mathrm{dB} Z$ echo height.

PR V7 2A25 algorithm uses $Z_{h}-R$ relationships to calculate rain rates at all reflectivities (Iguchi et al. 2009), WSR-88D commonly uses $R(\mathrm{KDP}, \mathrm{ZDR})$ or $R(\mathrm{KDP})$ relationships, where ZDR and KDP provide information on raindrop oblateness and number concentration that cannot be retrieved by TRMM PR. The increase in $1.5-\mathrm{km}$ altitude rain rates for WSR-88D changes slope above $50 \mathrm{~dB} Z$ while TRMM rain rates continue to increase exponentially. This change in the WSR-88D rain rate-reflectivity relationship is indicative of the algorithm's response to potential hail contamination and raindrop asphericity, which is further investigated in section 4.

The average $1.5-\mathrm{km}$ altitude rain rate for a given maximum $40-\mathrm{dB} Z$ height is shown for each dataset, where only data from columns with a maximum $40-\mathrm{dB} Z$ height of at least $1.5 \mathrm{~km}$ are shown in Fig. 6. WSR-88D rain rates at $1.5-\mathrm{km}$ altitude are consistently higher than TRMM-S and TRMM-Ku for all maximum 40-dBZ echo heights. TRMM-Ku and TRMM-S average rain rates show a slight upward trend for maximum $40-\mathrm{dB} Z$ heights above the melting level. WSR-88D trends similarly to TRMM-S and TRMM-Ku below the melting level (comparable to Fig. 4); however, above 5-km altitude, the factors causing the differences between TRMM PR and WSR-88D shown in Figs. 4 and 5 compound to produce large differences in WSR-88D and TRMM PR mean rain rates as a function of maximum $40-\mathrm{dB} Z$ height. Average rain rate increases from approximately 22 to $48 \mathrm{~mm} \mathrm{~h}^{-1}$ as maximum $40-\mathrm{dBZ}$ height increases from 4 to $14 \mathrm{~km}$ in the WSR-88D dataset, while TRMM-S only increases from approximately 15 to $24 \mathrm{~mm} \mathrm{~h}^{-1}$ over the same range of maximum $40-\mathrm{dB} Z$ heights.
Mean and median vertical reflectivity profiles for intervals of maximum $40 \mathrm{dBZ}$ are shown in Fig. 7. When the maximum $40-\mathrm{dB} Z$ height is below the $5-\mathrm{km}$ altitude (Fig. 7a), there is good agreement in the average and median reflectivity profiles across the three datasets, consistent with how each of the datasets vary similarly below 5-km altitude in Fig. 4. Once maximum 40-dBZ echo heights extend to between 5 and $6 \mathrm{~km}$, an offset between reflectivities in the different datasets appears in the rain region, with WSR-88D reflectivities higher than TRMM-Ku and TRMM-S reflectivities (consistent with Fig. 4). Mean and median profiles for more convectively intense columns with maximum $40-\mathrm{dB} Z$ heights between 10 and $15 \mathrm{~km}$, WSR-88D exhibits reflectivities that are $5 \mathrm{~dB}$ greater in rain regions and $2 \mathrm{~dB}$ greater in ice regions than TRMM-S. As illustrated in Fig. 7c, TRMM-Ku reflectivities are greater by approximately $2 \mathrm{~dB}$ than TRMM-S below 4-km altitude, in the rain region, and are less than TRMM-S by approximately $1 \mathrm{~dB}$ in assumed ice regions between 5 and $10 \mathrm{~km}$, which is caused by Mie scattering at $\mathrm{Ku}$ band. The growth of the offset between WSR-88D and TRMM-S mean and median reflectivity profiles with increasing maximum 40-dBZ height indicates that TRMM PR 2A25 V7 retrievals may be becoming increasingly biased toward lower reflectivity and rain rate as graupel and hail content increase in the column.

Variable filled joint histograms further comparing these three variables across the datasets are shown in Figs. $8-10$. Figure 8 shows median $1.5-\mathrm{km}$ altitude reflectivity as a function of the maximum $40-\mathrm{dB} Z$ height and $1.5-\mathrm{km}$ altitude rain rate. One of the notable differences between the WSR-88D dataset (Fig. 8a) and the TRMM-S dataset (Fig. 8b) is the shape of the joint distribution between maximum $40-\mathrm{dBZ}$ height and $1.5-\mathrm{km}$ altitude rain rate. Both datasets express their highest rain rates for maximum $40-\mathrm{dB} Z$ heights near or just above the $0^{\circ} \mathrm{C}$ level, between 4- and 6-km altitude. However, WSR$88 \mathrm{D}$ extends to higher rain rates (up to $\sim 120 \mathrm{~mm} \mathrm{~h}^{-1}$ ) than TRMM PR (up to $\sim 90 \mathrm{~mm} \mathrm{~h}^{-1}$ ), has higher rain rates for its most extreme maximum $40-\mathrm{dBZ}$ height (30$45 \mathrm{~mm} \mathrm{~h}^{-1}$ as compared with $0-20 \mathrm{~mm} \mathrm{~h}^{-1}$ ), and does not exhibit as steep a drop in extreme maximum $40-\mathrm{dBZ}$ heights as rain rates increase. The highest probability of extreme maximum $40-\mathrm{dB} Z$ heights corresponding with relatively low rain rates at $1.5-\mathrm{km}$ altitude is consistent with Fig. 3, where the most convectively intense columns do not correspond with the most intense rain rates. Because of their unique distribution shapes, the overlap fractions between the 90th, 95th, and 99th percentiles of the maximum $40-\mathrm{dBZ}$ echo height and $1.5-\mathrm{km}$ altitude rain rate vary in Table 2 , with WSR88D having greater overlap fractions in all percentiles, $\sim 50 \%$ higher overlap fraction than TRMM-S at the 

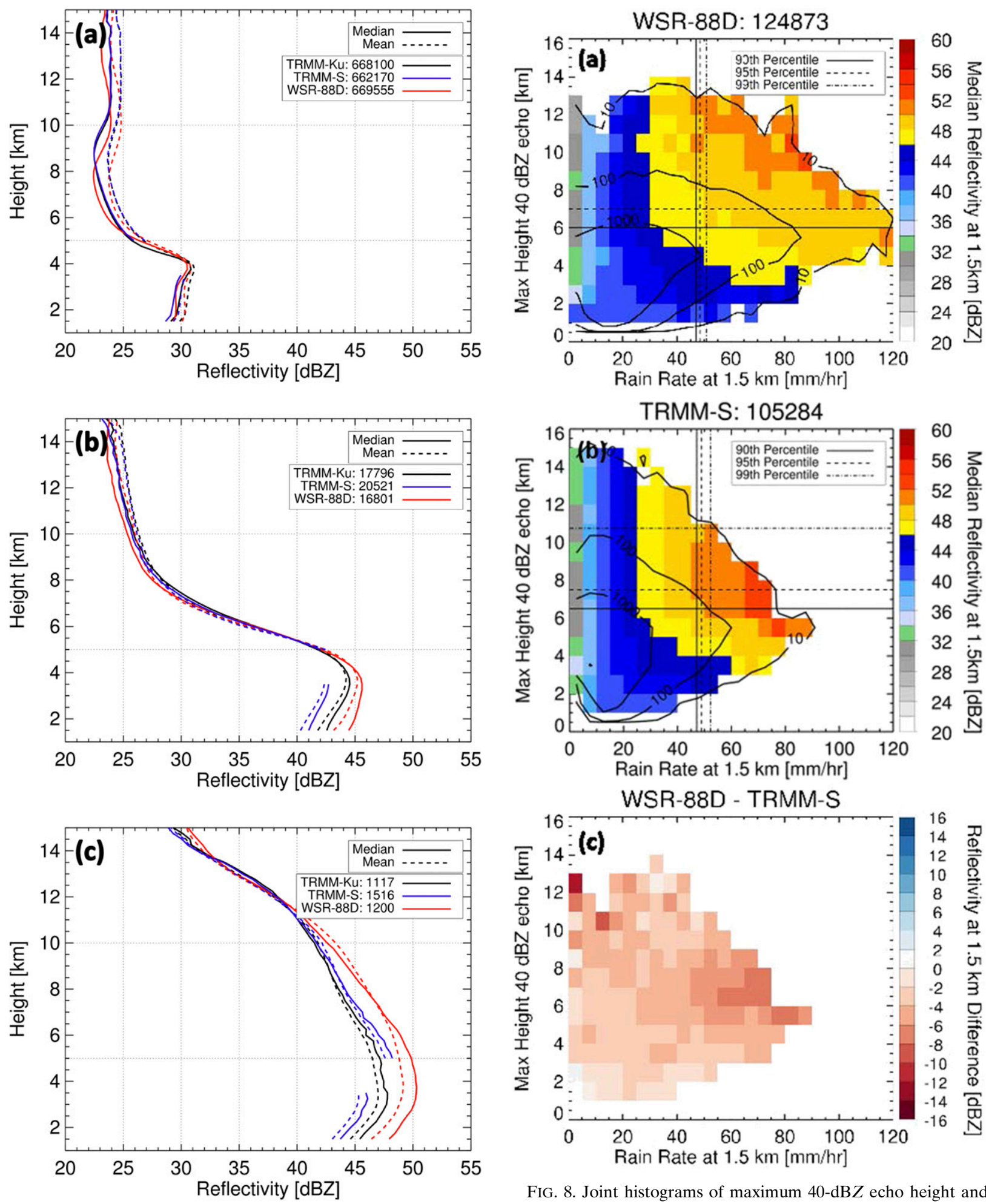

FIG. 7. Mean (dashed lines) and median (solid lines) vertical reflectivity profiles for systems with maximum $40-\mathrm{dBZ}$ echo heights between altitudes of (a) 0 and $5 \mathrm{~km}$, (b) 5 and $6 \mathrm{~km}$, and (c) 10 and $15 \mathrm{~km}$ for each of the three datasets: TRMM-Ku (black), TRMM-S (blue), and WSR-88D (red). The respective sample size of each dataset is listed in each panel.

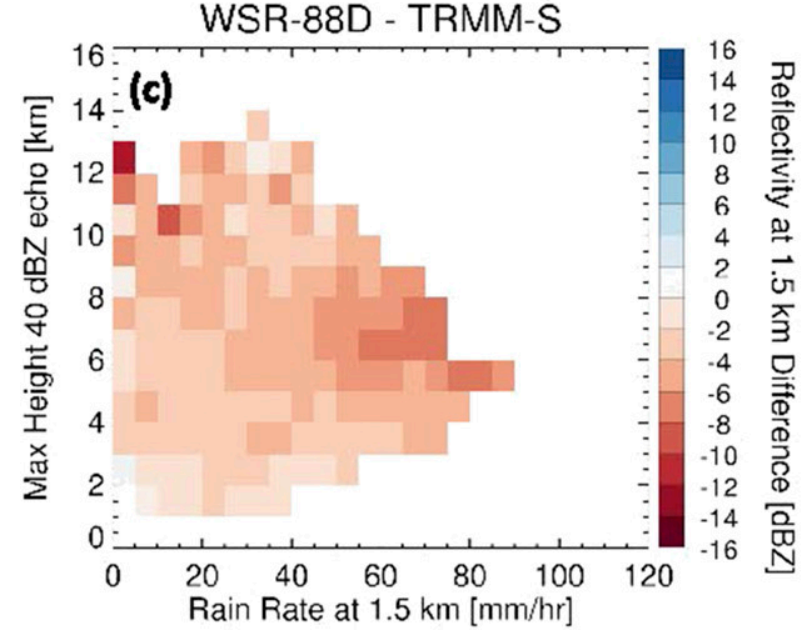

FIG. 8. Joint histograms of maximum 40-dBZ echo height and $1.5-\mathrm{km}$ altitude rain rate color filled with the median $1.5-\mathrm{km}$ altitude reflectivity in each bin for (a) WSR-88D and (b) TRMM-s, and (c) the difference between (a) and (b). A minimum 40-dBZ height threshold of $1.5 \mathrm{~km}$ is placed on the datasets, and the respective sample size for each dataset is listed above each figure. Black overlaid lines represent the 90th, (solid), 95th (dashed), and 99th (dot-dashed) percentile thresholds for each variable. Solid black contours represent the sample size within each 2D bin. 

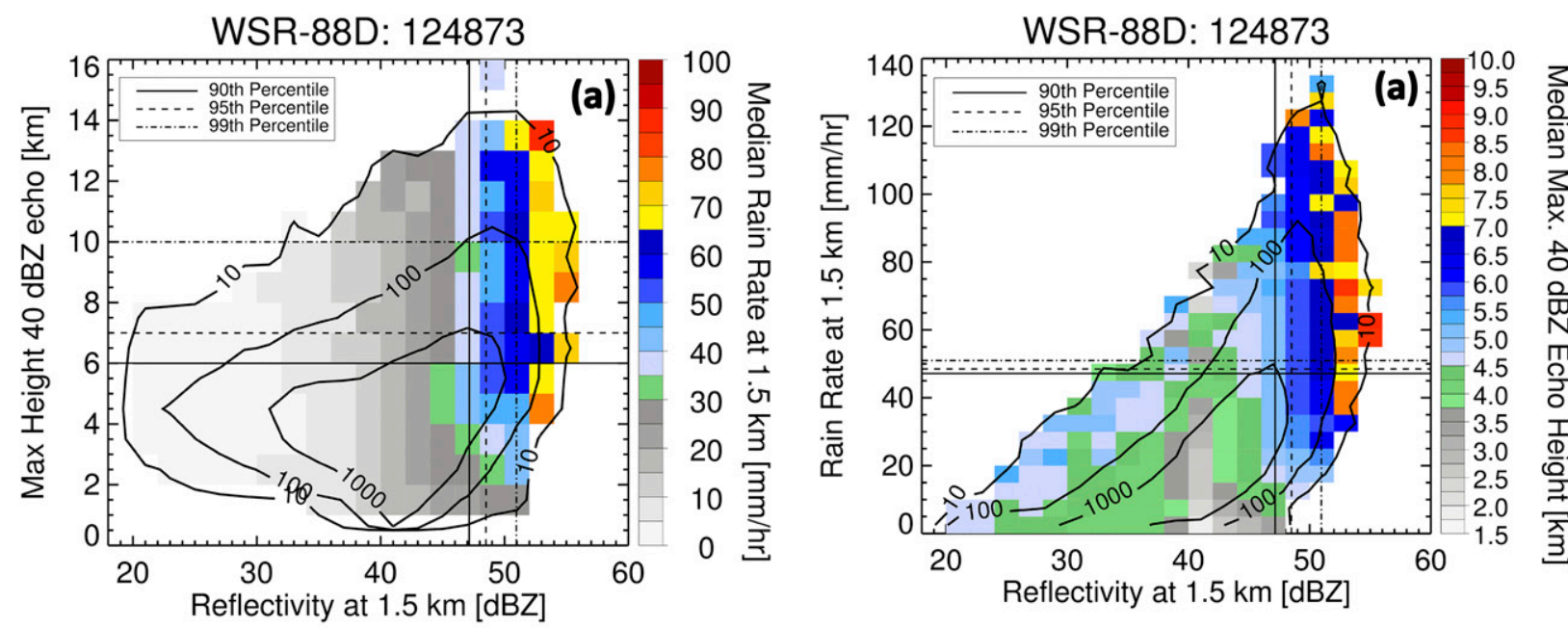

TRMM-S: 105284
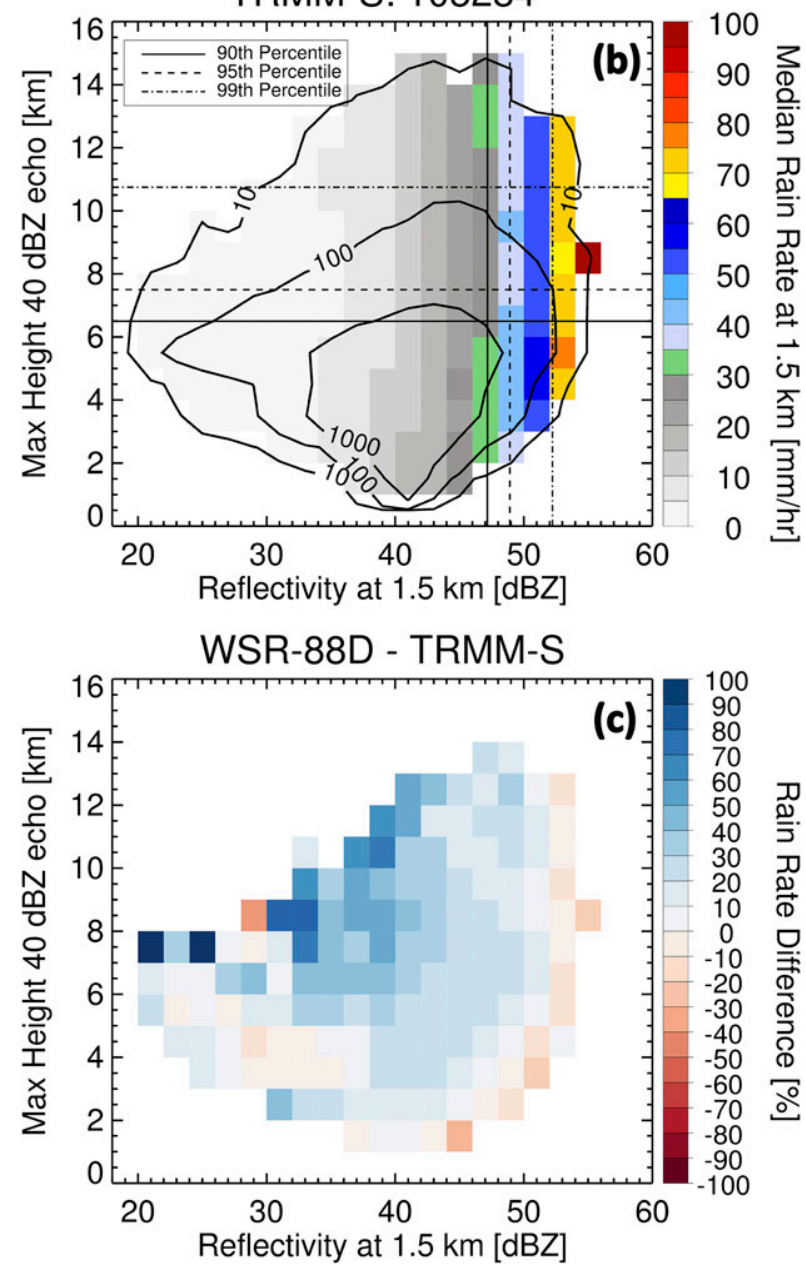

FIG. 9. As in Fig. 8, but reflectivity at $1.5-\mathrm{km}$ altitude and color filled with median rain rate at $1.5 \mathrm{~km}$, and (c) the difference in WSR-88D and TRMM-S rain rate.
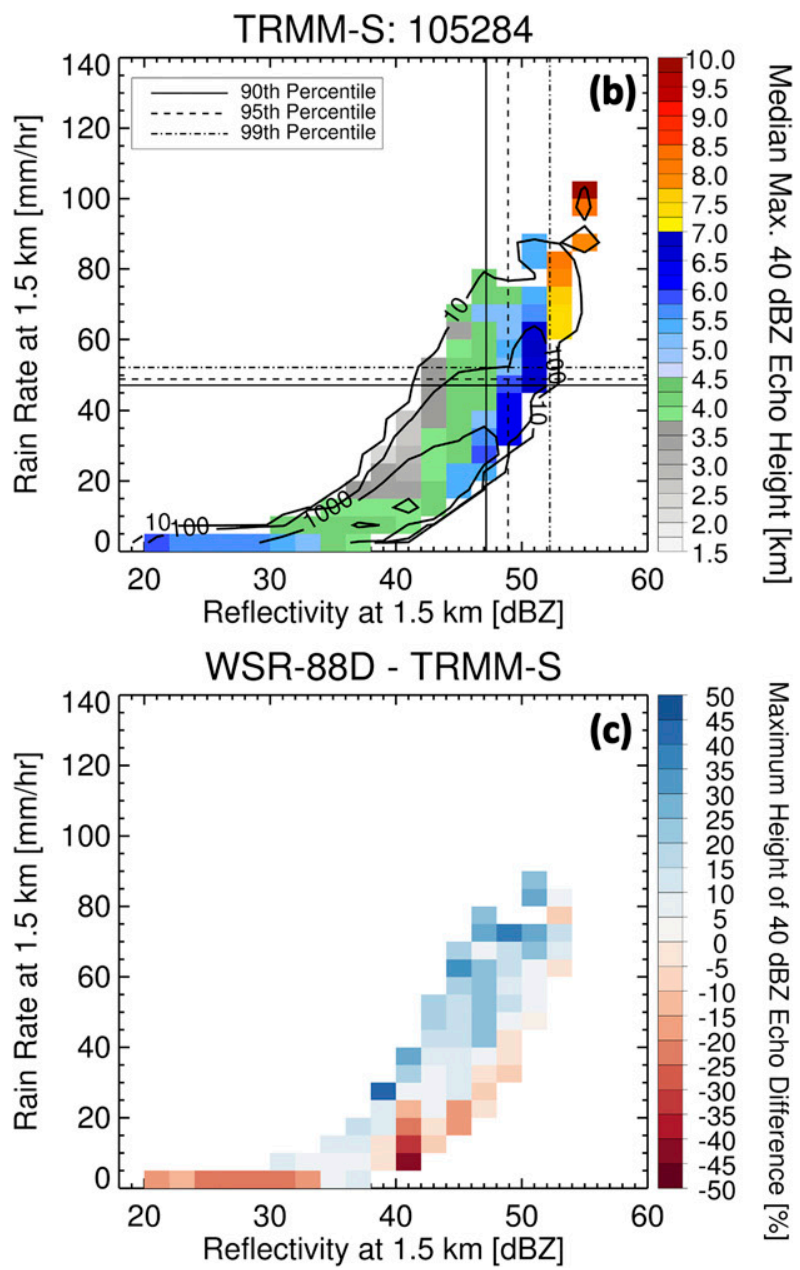

FIG. 10. As in Fig. 8, but for rain rate and reflectivity at $1.5-\mathrm{km}$ altitude, color filled with median maximum $40-\mathrm{dBZ}$ height in each bin. 
TABLE 2. Percentage of overlap of each dataset that exists in the 90th, 95th, and 99th percentiles of both maximum 40-dBZ heights and rain rates at $1.5-\mathrm{km}$ altitude from Figs. $8 \mathrm{a}$ and $8 \mathrm{~b}$.

\begin{tabular}{cccc}
\hline \hline Percentile & WSR-88D & TRMM-S & TRMM-Ku \\
\hline 90th & 34.2 & 22.8 & 24.7 \\
95th & 23.7 & 16.2 & 16.2 \\
99th & 9.7 & 7.4 & 8.4 \\
\hline
\end{tabular}

95th percentile, where the overlap fractions of WSR88D and TRMM-S are 0.23 and 0.16 , respectively.

At a given rain rate under $\sim 30 \mathrm{~mm} \mathrm{~h}^{-1}$, the median WSR-88D and TRMM-S $1.5-\mathrm{km}$ altitude reflectivities remain fairly constant with increasing maximum $40-\mathrm{dBZ}$ echo height above the melting level; however, a gradient appears for WSR-88D as rain rates increase above $40 \mathrm{~mm} \mathrm{~h}^{-1}$. WSR-88D $1.5-\mathrm{km}$ altitude reflectivity continues to increase with increasing maximum $40-\mathrm{dBZ}$ height for a given rain rate in this region, but for the TRMM-S datasets, $1.5-\mathrm{km}$ altitude reflectivity remains approximately constant with increasing maximum $40-\mathrm{dBZ}$ echo heights above $7 \mathrm{~km}$ for a given rain rate. Additionally, Fig. 8c shows that TRMM-S median 1.5-km altitude reflectivities are consistently higher for a given maximum $40-\mathrm{dB} Z$ height and $1.5-\mathrm{km}$ rain rate than those from WSR-88D, with the largest magnitude difference [(6-8) $\mathrm{dB} Z$ greater] for rain rates above $60 \mathrm{~mm} \mathrm{~h}^{-1}$ and maximum $40-\mathrm{dB} Z$ heights above $5 \mathrm{~km}$.

Figure 9 shows the relationship between maximum $40-\mathrm{dB} Z$ height and $1.5-\mathrm{km}$ altitude reflectivity color filled with median $1.5-\mathrm{km}$ altitude rain rate. Both datasets exhibit a similar shape in their joint distributions. However, WSR-88D (Fig. 9a) expresses a peak in the probability of extreme maximum $40-\mathrm{dB} Z$ echo heights at greater $1.5-\mathrm{km}$ altitude reflectivities, between 46 and $52 \mathrm{~dB} Z$, than TRMM-S (Fig. 9b), which has highest probabilities between 40 and $50 \mathrm{~dB} Z$. Because of this, Table 3 shows that the overlap fractions of extreme maximum $40-\mathrm{dB} Z$ heights and extreme $1.5-\mathrm{km}$ altitude reflectivities are once again higher for WSR-88D (35\% overlap at the 95 th percentile) than TRMM-Ku (11\% overlap at the 95th percentile) and TRMM-S (55\% overlap at the 95th percentile). For TRMM-S, rain rates at a given reflectivity are nearly constant or decrease as maximum $40-\mathrm{dB} Z$ echo height increases, whereas they increase slightly within the WSR-88D dataset. With an exception for $1.5-\mathrm{km}$ altitude reflectivities greater than $52 \mathrm{~dB} Z$, the difference in rain rates (Fig. 9c) between WSR-88D and the TRMM-S dataset reveals that WSR-88D has generally higher retrieved rain rates than TRMM-S for a given maximum $40-\mathrm{dBZ}$ height and $1.5-\mathrm{km}$ reflectivity. This is especially true for maximum $40-\mathrm{dB} Z$ heights greater
TABLE 3. Percentage of overlap of each dataset that exists in the 90th, 95th, and 99th percentiles of both maximum 40-dBZ heights and reflectivity at $1.5-\mathrm{km}$ altitude from Figs. $9 \mathrm{a}$ and $9 \mathrm{~b}$.

\begin{tabular}{cccc}
\hline \hline Percentile & WSR-88D & TRMM-S & TRMM-Ku \\
\hline 90th & 44.7 & 21.2 & 34 \\
95th & 35.2 & 14.3 & 23.4 \\
99th & 19.8 & 5.5 & 11.2 \\
\hline
\end{tabular}

than $5 \mathrm{~km}$ with $1.5-\mathrm{km}$ reflectivities between 30 and $44 \mathrm{dBZ}$, where WSR-88D rain rates are a fraction of $30 \%-90 \%$ higher.

Figure 10 shows the relationship between $1.5-\mathrm{km}$ altitude reflectivity and $1.5-\mathrm{km}$ altitude rain rate color filled with the median of the maximum 40-dBZ echo height in each bin. There exists a notable difference in the shape of the joint distributions between the WSR-88D dataset (Fig. 10a) and TRMM-S (Fig. 10b) datasets. While both datasets exhibit an increase in rain rate with increasing reflectivity, WSR-88D has much more variable rain rates for a given reflectivity and a much wider range of reflectivities for a given rain rate than the TRMM-S datasets. For example, for a $1.5-\mathrm{km}$ altitude rain rate of $20 \mathrm{~mm} \mathrm{~h}^{-1}$, WSR-88D $1.5-\mathrm{km}$ reflectivity ranges from $\sim(25-52) \mathrm{dB} Z$, as opposed to $\sim(35-49) \mathrm{dB} Z$ for TRMM-S. This results in TRMM-Ku and TRMM-S possessing higher overlap fractions in Table 4 between extreme low-level rain rates and reflectivities, 0.67 and 0.66 , respectively, at the 95th percentile, than WSR-88D, which has an overlap fraction of approximately 0.23 at the 95 th percentile. The datasets also differ in their maximum 40-dBZ echo heights for a given reflectivity-rain-rate bin. In the WSR-88D dataset, for a given $1.5-\mathrm{km}$ altitude reflectivity, as rain rate increases, so does the maximum $40-\mathrm{dB} Z$ echo height. However, in the TRMM and TRMM-S datasets, the opposite is true. Thus, in the TRMM datasets, relatively weak convection, as judged by the maximum height of the 40-dBZ echo, will have a higher mean $1.5-\mathrm{km}$ altitude rain rate for a given $1.5 \mathrm{~km}$ reflectivity than relatively intense convection, while the opposite is true for WSR-88D. This contrast can be seen in the difference plot (Fig. 10c), where WSR-88D maximum 40-dBZ heights for a given $1.5-\mathrm{km}$ reflectivity are between $10 \%$ and $25 \%$ higher for more intense $1.5-\mathrm{km}$ altitude rain rates and between $5 \%$ and $25 \%$ lower for weaker rain rates.

\section{b. PIA, KDP, ZDR, and hail fraction analysis}

TRMM PIA, and WSR-88D hail fraction, KDP, and ZDR are examined in an effort to identify potential sources for the differences detailed in section $4 \mathrm{a}$. Figure 11 shows joint histograms of maximum $40-\mathrm{dB} Z$ echo heights and $1.5-\mathrm{km}$ altitude reflectivity for 
TABLE 4. Percentage of overlap of each dataset that exists in the 90th, 95th, and 99th percentiles of both rain rates and reflectivity at $1.5-\mathrm{km}$ altitude from Figs. 10a and 10b.

\begin{tabular}{cccc}
\hline \hline Percentile & WSR-88D & TRMM-S & TRMM-Ku \\
\hline 90th & 56.7 & 71.1 & 72.2 \\
95th & 46.1 & 66.4 & 67.2 \\
99th & 22.9 & 61.7 & 61.5 \\
\hline
\end{tabular}

TRMM-S and WSR-88D, color filled with median PIA (Fig. 11a), hail fraction (Fig. 11b), KDP (Fig. 11c), and ZDR (Fig. 11d).

PIA is considered one of the primary sources of uncertainty in the TRMM PR 2A25 rain-rate algorithm (Iguchi et al. 2009). Figure 11a shows that the highest values of PIA are associated with the largest $1.5-\mathrm{km}$ altitude reflectivities (above $\sim 50 \mathrm{dBZ}$ ). It also shows that PIA increases with increasing maximum $40-\mathrm{dBZ}$ height for a given $1.5-\mathrm{km}$ altitude reflectivity. For example, for a $1.5-\mathrm{km}$ altitude reflectivity of $45 \mathrm{~dB} Z$ and a maximum $40-\mathrm{dB} Z$ echo height of $4 \mathrm{~km}$, the median PIA is around $5-6 \mathrm{~dB}$. However, for the same $1.5-\mathrm{km}$ altitude reflectivity with a maximum $40-\mathrm{dBZ}$ echo height of $8 \mathrm{~km}$, the median PIA is $\sim 9 \mathrm{~dB}$. With the highest PIA estimates being associated with the highest $1.5-\mathrm{km}$ altitude reflectivities, and their increase with convective intensity, it is apparent that the extreme convective intensities and rain rates that are the focus in this study are prone to significant column-integrated attenuation. In addition to possible bias in the PIA estimate in conditions of very heavy precipitation and nonuniform beamfilling (Kozu and Iguchi 1999; Short et al. 2013), another source of error lies in the assumed distribution of attenuation throughout the data column during the attenuation correction. The greater the PIA, the greater the potential for errors in attenuation-corrected reflectivity. TRMM PR's V7 2A25 algorithm assumes that rain exists below the melting level with a transition in the specific attenuation value from liquid values to ice values in a $\sim 2.5-\mathrm{km}$ layer above the melting level in convective regions (Iguchi et al. 2009). These assumptions and assumed particle size distributions are especially questionable in situations where hail dominates the backscattered signal below the melting
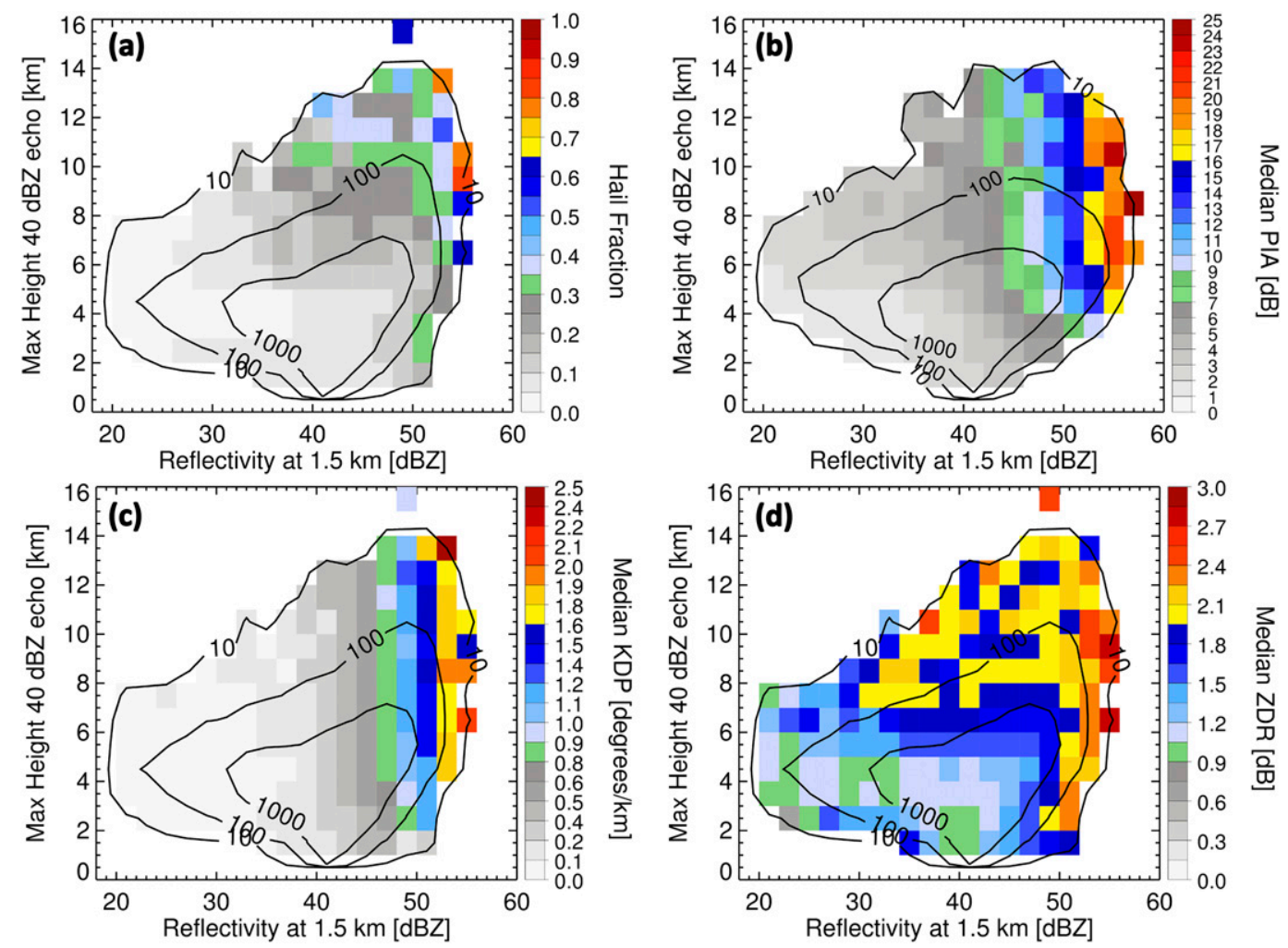

FIG. 11. Variable filled joint histograms of (a) WSR-88D maximum 40-dBZ echo height and 1.5-km altitude reflectivity color filled with hail fraction, (b) TRMM PR maximum 40-dBZ echo height and $1.5-\mathrm{km}$ altitude reflectivity color filled with median PIA, (c) WSR-88D maximum 40-dBZ echo height and $1.5-\mathrm{km}$ altitude reflectivity color filled with median KDP, and (d) WSR-88D maximum 40-dBZ echo height and $1.5-\mathrm{km}$ altitude reflectivity color filled with median ZDR. A minimum 40-dBZ height threshold of $1.5 \mathrm{~km}$ is placed on the datasets, and the sample size for these figures is 130560 columns for (a) and 124873 columns for (b)-(d). 
level or liquid is not present in significant quantities above the melting level. These potentially erroneous assumptions may lead to low-level reflectivity attenuation-correction biases that negatively impact retrieved rain rates, arguably producing part of the differences with WSR-88D results shown in section 4 a.

In an effort to understand the potential errors in phase assumptions, WSR-88D hail fraction at $1.5-\mathrm{km}$ altitude is analyzed. Hail fraction is defined as the fraction of pixels at $1.125-\mathrm{km}$ resolution within a $4.5-\mathrm{km}$ footprint that have a PID indicative of rain mixed with hail or graupel. Recall that pixels identified as ice alone are not included in the analysis since a retrieval of rain rate is not possible for these points. Figure $11 \mathrm{~b}$ shows that the lowest hail fractions at $1.5-\mathrm{km}$ altitude are associated with lower $1.5-\mathrm{km}$ altitude reflectivities and maximum 40-dBZ echo heights that do not extend above the freezing level. Higher hail fractions at $1.5-\mathrm{km}$ altitude are collocated with the greatest $1.5-\mathrm{km}$ altitude reflectivities (greater than $50 \mathrm{~dB} Z$ ) and the highest maximum $40-\mathrm{dB} Z$ heights $(>8 \mathrm{~km})$. This suggests that the high $1.5-\mathrm{km}$ altitude rain rates that TRMM PR produces at large $1.5-\mathrm{km}$ altitude reflectivities (Fig. 5) are likely hail contaminated. Figure 11a shows that PIA was also large in these conditions, and therefore, the attenuation correction under these conditions likely has erroneous phase and particle size distribution assumptions in the TRMM PR 2A25 V7 algorithm. This impacts the TRMM attenuation-corrected reflectivity profile because ice has a specific attenuation that is an order of magnitude less than liquid for large reflectivities Iguchi et al. 2009).

In addition to hail, assumed properties of rain can also cause biases in the 2A25 V7 algorithm, and these are investigated via WSR-88D measurements of KDP and ZDR. Unlike PIA, Fig. 11c shows that KDP expresses little sensitivity to the maximum height of the $40-\mathrm{dB} Z$ echo. For example, at $1.5-\mathrm{km}$ altitude reflectivities of $\sim 45 \mathrm{dBZ}$, KDP remains $\sim\left(0.5^{\circ}-0.6^{\circ}\right) \mathrm{km}^{-1}$ regardless of the maximum 40-dBZ height. The largest KDP values are associated with the highest $1.5-\mathrm{km}$ altitude reflectivities, and therefore the highest $1.5-\mathrm{km}$ altitude rain rates. Superior rain-rate information is provided by KDP in situations of heavy rain or hail mixed with rain (Cifelli et al.2011), but this information is not retrievable by TRMM PR, and these situations also have significant PIA. The large KDP values indicate large concentrations of raindrops that have oblateness, indicating that raindrop size distributions may be unique in these cases and possibly inconsistent with assumptions used in the V7 2A25 retrieval.

This issue is further informed by Fig. 11d, where positive ZDR indicates the presence of oblate raindrops at $1.5-\mathrm{km}$ altitude. Figure $11 \mathrm{~d}$ shows that for all columns with maximum $40-\mathrm{dB} Z$ echo heights above $8 \mathrm{~km}$, median ZDR varies from 1.5 to $3 \mathrm{~dB}$. Strongly positive values of ZDR also exist for lesser maximum $40-\mathrm{dBZ}$ echo heights where the $1.5-\mathrm{km}$ altitude reflectivity is greater than $50 \mathrm{~dB} Z$. These regions indicate situations with large, oblate raindrops that TRMM is not able to detect, therefore preventing a more accurate rain-rate retrieval for these high reflectivity and high maximum 40-dBZ height situations. From Fig. 11b, it is known that one area of strongly positive ZDR in Fig. 11d coincides with significant hail fraction, which may indicate that large, oblate raindrops are associated with melted hail or graupel particles, again suggesting that raindrop size distributions and their associated attenuation may be unique and different from what is assumed in the V7 2A25 retrieval for situations of high low-level reflectivities and high maximum $40-\mathrm{dB} Z$ heights.

\section{Conclusions}

The TRMM satellite has produced an invaluable 17-yr dataset of precipitation retrievals over the tropics and subtropics. This study uses TRMM PR 2A25 V7 retrievals to examine the overlap between extreme rain rates and extreme convective intensities. While it is often assumed that extreme convectively intense precipitation features produce extreme rainfall rates, Hamada et al. (2015) showed that this is frequently not the case and that extreme rain rates are commonly found in convection of moderate strength. It is well known, however, that intense convection poses special difficulties for the TRMM PR operating at a $\mathrm{Ku}$ band because of its susceptibility to attenuation, especially by liquid and/or partially melted hydrometeors (Iguchi et al. 2009). This is a serious issue for two reasons: 1) estimates of PIA are subject to significant error, and 2) distributing the PIA as a function of height involves assumptions that may produce reflectivity and rain-rate profile biases in intense deep convection. It is therefore important to quantify potential biases in the TRMM PR-retrieved reflectivity profiles and low-level rain rates that may result from TRMM PR attenuationcorrection and $Z-R$ relationship assumptions that are inappropriate for intense, deep convection. This is accomplished by comparing TRMM PR retrievals against S-band observations with minimal attenuation from NOAA WSR-88D instruments. In addition to operating at S band, WSR-88Ds are capable of retrieving additional variables using dual-polarization such as KDP, $\mathrm{ZDR}$, and particle identification, which allow for more informed decisions in the rain-rate relationships used to calculate corresponding rain rates. In this study, we 
conduct intercomparisons of $1.5-\mathrm{km}$ reflectivity, $1.5-\mathrm{km}$ rain rate, and the maximum height of the $40-\mathrm{dB} Z$ echo across three datasets of radar retrievals: TRMM-Ku, TRMM-S, and WSR-88D.

Initial investigations into the overlap between extreme convective intensity and extreme rain rate, across the tropics and subtropics echo the findings of Hamada et al. (2015), where there exists a low amount of overlap between the two extremes in both the PF and columndata perspectives. However, the aforementioned issues in the TRMM PR 2A25 algorithm make this overlap conclusion uncertain. To investigate this uncertainty, TRMM PR reflectivity and rain-rate retrievals from 2002 to 2014 are further compared against WSR-88D S-band retrievals from 2013 over the SEUS for the months of June, July, and August.

WSR-88D, TRMM-Ku, and TRMM-S reflectivities at $1.5-\mathrm{km}$ altitude exhibit consistent differences when the maximum $40-\mathrm{dB} Z$ echo height of a column exceeds above the melting level (approximately $4-5 \mathrm{~km}$ in the SEUS in JJA). For more convectively intense systems, at a given maximum $40-\mathrm{dB} Z$ echo height exceeding 5-km altitude, WSR-88D measures reflectivities of approximately $2 \mathrm{~dB}$ higher than both TRMM datasets. In addition, when $1.5-\mathrm{km}$ reflectivities exceed $\sim 33 \mathrm{~dB} Z$, WSR-88D calculated $1.5-\mathrm{km}$ rain rates are greater than TRMM PR $1.5-\mathrm{km}$ rain rates by $5-20 \mathrm{~mm} \mathrm{~h}^{-1}$. The aforementioned factors combine to produce significantly higher rain rates $\left(\sim 20 \mathrm{~mm} \mathrm{~h}^{-1}\right.$ greater $)$ in the WSR-88D dataset at a given maximum $40-\mathrm{dB} Z$ echo height than exist in either the TRMM-Ku or TRMM-S datasets. Mean vertical profiles of reflectivity show that TRMM PR and WSR-88D reflectivity differences below the melting level increase as convective intensity increases, with WSR-88D exceeding TRMM reflectivities, further indicating that the TRMM PR 2A25 V7 retrievals become increasingly biased toward lower reflectivity and rain rate as graupel and/or hail content increase in the column. The overlap of the 99th percentile of $1.5-\mathrm{km}$ rain rates with the 99th percentile of convective intensities is small in both the TRMM PR and WSR-88D datasets over the SEUS. However, the overlap percentage is $30 \%$ larger in the WSR-88D dataset, showing that TRMM retrievals within convectively intense columns are likely biased toward lower near-surface reflectivities and rain rates.

Examinations of PIA, KDP, ZDR, and hail fraction provide insight to potential causes of differences between WSR-88D and TRMM PR retrievals. Mean TRMM PR PIA increases with increasing maximum $40-\mathrm{dB} Z$ echo heights between altitudes of 5 and $9 \mathrm{~km}$, indicating the potential for attenuation-correction biases. $1.5-\mathrm{km}$ altitude hail fraction, retrieved using a
WSR-88D PID algorithm, increases with increasing maximum $40-\mathrm{dB} Z$ height and $1.5-\mathrm{km}$ reflectivity, indicating that the TRMM PR attenuation-correction algorithm is possible misidentifying low-midlevel ice as greater attenuating liquid in these cases. Mean WSR-88D KDP and ZDR both increase with increasing rain rates and reflectivities, meaning drop size distributions are changing with reflectivity and rain rate in a manner that is not observable by TRMM PR. Mean ZDR levels off once rain rates reach $40 \mathrm{~mm} \mathrm{~h}^{-1}$, but the highest values of KDP are associated with the highest rain rates and reflectivities, which are also areas of significant mean PIA for TRMM PR.

Overall, comparisons between WSR-88D and TRMM PR indicate that the errors in the estimated PIA and/or attenuation-correction method (assumed phase, particle size distribution, and/or attenuation coefficients) in the $2 \mathrm{~A} 25 \mathrm{~V} 7$ algorithm are contributing to low-level reflectivities that are biased low when the maximum 40-dBZ echo height extends above the melting level. The presence of graupel or hail in the column and potentially unique low-level raindrop size distributions in such cases that could be systematically different from the ones assumed in 2A25 V7. Additionally, nonuniform beamfilling often results in underestimation of PIA (Kozu and Iguchi 1999; Short et al. 2013). This is consistent with the presented results in that TRMM PR attenuation-corrected reflectivities are lower than WSR-88D reflectivities throughout most of the vertical column. This indicates that PIA is not sufficiently large to fully correct the reflectivity profile. Usage of KDP to retrieve high rain rates within the WSR-88D data also indicates that the $2 \mathrm{~A} 25 \mathrm{~V} 7 \mathrm{Z}-R$ relationships may be underestimating rain rates for intense convection, except in rare situations of extreme low-level reflectivity exceeding $55 \mathrm{~dB} Z$, where the $Z-R$ relationship overestimates rain rate because of likely hail contamination.

We note that our results are dependent on 2013 WSR-88D data being representative. It is possible that WSR-88D data from other years may be slightly different and alter the quantified differences between TRMM and WSR-88D data presented in this study. Future work should analyze more years of WSR-88D JJA data to test the robustness of this study's results. Future research should also investigate individual cases to separate the roles of nonuniform beamfilling and misidentification of hydrometeor phase in producing differences between satellite and ground radar retrievals.

Acknowledgments. This work was supported by NASA under Grant NNX16AD76G. Level 1 and 2 TRMM PR data were accessed (on 1 July 2016; subset used was June-August 2002-13) through the University of 
Utah TRMM database, compiled by Chuntao Liu, and are freely available online (http://trmm.chpc.utah.edu). WSR-88D level 2 datasets, hosted by NOAA and the NCDC, were accessed in July 2016 and can be downloaded from https://www.ncdc.noaa.gov/nexradinv/. The authors also thank Mike Dixon and the University Corporation for Atmospheric Research for providing the RadX processing software used to interpret the WSR-88D data (https://github.com/NCAR/lrose-core, https://www.eol. ucar.edu/content/lidarradar-open-software-environment). Last, the authors thank the University of Utah Center for High Performance Computing for providing the computing support.

\section{REFERENCES}

Amitai, E., D. B. Wolff, D. A. Marks, and D. Silberstein, 2002: Radar rainfall estimation: Lessons learned from the NASA/ TRMM validation program. Second European Conf. on Radar Meteorology (ERAD), Delft, Netherlands, ERAD Publication Series 1, 255-260.

Bolen, S. M., and V. Chandrasekar, 2000: Quantitative cross validation of space-based and ground-based radar observations. J. Appl. Meteor., 39, 2071-2079, https://doi.org/10.1175/ 1520-0450(2001)040<2071:QCVOSB > 2.0.CO;2.

Brandes, E. A., A. V. Ryzhkov, and D. S. Zrnić, 2001: An evaluation of radar rainfall estimates from specific differential phase. J. Atmos. Oceanic Technol., 18, 363-375, https:// doi.org/10.1175/1520-0426(2001)018<0363:AEORRE > 2.0.CO;2.

, G. Zhang, and J. Vivekanandan, 2002: Experiments in rainfall estimation with a polarimetric radar in a subtropical environment. J. Appl. Meteor., 41, 674-685, https://doi.org/ 10.1175/1520-0450(2002)041<0674:EIREWA>2.0.CO;2.

Cao, Q., Y. Hong, Y. Qi, Y. Wen, J. Zhang, J. J. Gourley, and L. Liao, 2013: Empirical conversion of the vertical profile of reflectivity from Ku-band to S-band frequency. J. Geophys. Res. Atmos., 118, 1814-1825, https://doi.org/10.1002/jgrd.50138.

Chandrasekar, V., A. Hou, E. Smith, V. N. Bringi, S. A. Rutledge, E. Gorgucci, W. A. Petersen, and G. S. Jackson, 2008: Potential role of dual-polarization radar in the validation of satellite precipitation measurements: Rationale and opportunities. Bull. Amer. Meteor. Soc., 89, 1127-1145, https://doi.org/ 10.1175/2008BAMS2177.1.

Cifelli, R., V. Chandrasekar, S. Lim, P. C. Kennedy, Y. Wang, and S. A. Rutledge, 2011: A new dual-polarization radar rainfall algorithm: Application in Colorado precipitation events. J. Atmos. Oceanic Technol., 28, 352-364, https://doi.org/ 10.1175/2010JTECHA1488.1.

Hamada, A., Y. N. Takayabu, C. Liu, and E. J. Zipser, 2015: Weak linkage between the heaviest rainfall and tallest storms. Nat. Commun., 6, 6213, https://doi.org/10.1038/ncomms7213.

Hitschfeld, W., and J. Bordan, 1954: Errors inherent in the radar measurement of rainfall at attenuating wavelengths. J. Meteor., 11, 58-67, https://doi.org/10.1175/1520-0469(1954)011<0058: EIITRM $>2.0 . \mathrm{CO} ; 2$.

Iguchi, T., and R. Meneghini, 1994: Intercomparison of singlefrequency methods for retrieving a vertical rain profile from airborne or spaceborne radar data. J. Atmos. Oceanic Technol., 11, 1507-1516, https://doi.org/10.1175/1520-0426(1994)011<1507: IOSFMF $>2.0 . \mathrm{CO} ; 2$
,-- J. Awaka, T. Kozu, and K. Okamoto, 2000: Rain profiling algorithm for TRMM Precipitation Radar data. Adv. Space Res., 25, 973-976, https://doi.org/10.1016/S0273-1177(99)00933-3.

_ - T. Kozu, J. Kwiatkowski, R. Meneghini, J. Awaka, and K. Okamoto, 2009: Uncertainties in the rain profiling algorithm for the TRMM Precipitation Radar. J. Meteor. Soc. Japan, 87A, 1-30, https://doi.org/10.2151/jmsj.87A.1.

Istok, M. J., and Coauthors, 2009: WSR-88D dual polarization initial operational capabilities. 25th Conf. on Int. Interactive Information and Processing Systems (IIPS) for Meteorology, Oceanography, and Hydrology, Phoenix, AZ, Amer. Meteor. Soc., 15.5, https://ams.confex.com/ams/pdfpapers/ 148927.pdf.

Kessinger, C., S. Ellis, and J. Van Andel, 2003: The radar echo classifier: A fuzzy logic algorithm for the WSR-88D. Third Conf. on Artificial Intelligence Applications to the Environmental Science, Long Beach, CA, Amer. Meteor. Soc., P1.6, https://ams.confex.com/ams/pdfpapers/54946.pdf.

Kirstetter, P.-E., Y. Hong, J. J. Gourley, M. Schwaller, W. Petersen, and J. Zhang, 2012: Comparison of TRMM 2A25 products, version 6 and version 7, with NOAA/NSSL ground radar-based National Mosaic QPE. J. Hydrometeor., 14, 661-669, https://doi.org/10.1175/JHM-D-12-030.1.

Kozu, T., and T. Iguchi, 1999: Nonuniform beamfilling correction for spaceborne radar rainfall measurement: Implications from TOGA COARE radar data analysis. J. Atmos. Oceanic Technol., 16, 1722-1735, https://doi.org/10.1175/1520-0426(1999)016<1722: NBCFSR $>2.0 . \mathrm{CO} ; 2$.

,-- T. Kubota, N. Yoshida, S. Seto, J. Kwiatkowski, and Y. N. Takayabu, 2009: Feasibility of raindrop size distribution parameter estimation with TRMM Precipitation Radar. J. Meteor. Soc. Japan, 87A, 53-66, https://doi.org/10.2151/jmsj.87A.53.

Liao, L., and R. Meneghini, 2009: Validation of TRMM precipitation radar through comparison of its multiyear measurements with ground-based radar. J. Appl. Meteor. Climatol., 48, 804 817, https://doi.org/10.1175/2008JAMC1974.1.

Liu, C., E. J. Zipser, D. J. Cecil, S. W. Nesbitt, and S. Sherwood, 2008: A cloud and precipitation feature database from nine years of TRMM observations. J. Appl. Meteor. Climatol., 47, 2712-2728, https://doi.org/10.1175/2008JAMC1890.1.

Marks, D. A., and Coauthors, 2000: Climatological processing and product development for the TRMM ground validation program. Phys. Chem. Earth, 25B, 871-875, https://doi.org/ 10.1016/S1464-1909(00)00118-0.

Melnikov, V., D. Zrnic, A. Free, R. Ice, and R. Maceman, 2017: Monitoring radar calibration using ground clutter. WSR-88D Radar Operations Center, Applications Branch, 21 pp., https://www.nssl.noaa.gov/publications/wsr88d_reports/ Z_ZDRcal_ROC_MOU_report_2017.pdf.

Meneghini, R., T. Iguchi, T. Kozu, L. Liao, K. Okamoto, J. A. Jones, and J. Kwiatkowski, 2000: Use of the surface reference technique for path attenuation estimates from the TRMM Precipitation Radar. J. Appl. Meteor., 39, 2053-2070, https://doi.org/10.1175/1520-0450(2001)040<2053: UOTSRT $>2.0 . \mathrm{CO} ; 2$.

NWS Radar Operations Center, 1991: NOAA Next Generation Radar (NEXRAD) level 2 base data. NOAA National Centers for Environmental Information. Subset used: July-August 2013, accessed 1 July 2016, https://doi.org/10.7289/V5W9574V.

Ryzhkov, A. V., and D. S. Zrnić, 1995: Comparison of dualpolarization radar estimators of rain. J. Atmos. Oceanic Technol., 12, 249-256, https://doi.org/10.1175/1520-0426(1995)012<0249: CODPRE $>2.0 . \mathrm{CO} ; 2$. 
Short, D., K. Nakagawa, and T. Iguchi, 2013: Reduction of nonuniform beam filling effects by vertical decorrelation: Theory and simulations. J. Meteor. Soc. Japan, 91, 539-543, https:// doi.org/10.2151/jmsj.2013-408.

Wolff, D. B., D. A. Marks, E. Amitai, D. S. Silberstein, B. L. Fisher, A. Tokay, J. Wang, and J. L. Pippitt, 2005: Ground validation for the Tropical Rainfall Measuring Mission (TRMM). J. Atmos. Oceanic Technol., 22, 365-380, https://doi.org/ 10.1175/JTECH1700.1.
Zipser, E. J., and K. R. Lutz, 1994: The vertical profile of radar reflectivity of convective cells: A strong indicator of storm intensity and lightning probability? Mon. Wea. Rev., 122, 1751-1759, https://doi.org/10.1175/1520-0493(1994)122<1751: TVPORR $>2.0 . \mathrm{CO} ; 2$.

, D. J. Cecil, C. Liu, S. W. Nesbitt, and D. P. Yorty, 2006: Where are the most intense thunderstorms on Earth? Bull. Amer. Meteor. Soc., 87, 1057-1071, https://doi.org/10.1175/ BAMS-87-8-1057. 